\title{
MÁRIO DE ANDRADE NA AMAZÔNIA: A ESCRITA POÉTICA DE UMA VIAGEM
}

Rosa Veloso Dias Giannaccini*

RESUMO:

Este estudo anal isa a viagem de Mário de Andrade à Amazônia, procurando avaliar a obra "O Turista Aprendiz" no contexto do Modernismo. Para isso, vale-se de teóricos que investigam a obra do autor assim como esse momento na literatura brasileira. Examina a representação da Amazônia nos textos dos viajantes estrangeiros em contraponto ao olhar modernista de Mário de Andrade. Analisa algumas imagens fotográficas realizadas por ele ao longo da viagem e o seu papel de colecionador de bens culturais e de defensor do patrimônio cultural brasileiro.

PALAVRAS-CHAVE: Mário de Andrade, modemismo, Amazônia, viagem.

Entre os meses de maio e agosto de 1927, Mário de Andrade, juntamente com alguns poucos amigos, "curiosos de conhecer outros brasis", realiza sua primeira e única viagem ao Norte do Brasil, a qual chamou de "viagem etnográfica". Ao darThe esse nome, o escritor naturalmente desejava acentuar o caráter de estudo descritivo da cultura do povo amazônico, com a qual já tinha contato através de diversos textos, e que vinha sendo aproveitada na elaboração de sua obra de ficção Macunaíma, publicada no ano seguinte ao da viagem, em 1928. Ao planejar a excursão, esperava fazê-la acompanhado de uma grande comitiva, mas acaba tendo por companhia apenas Dona 01 ivia Guedes Penteado, dama da aristocracia cafeeira, mecenas dos modernistas e personalidade de relevo em São Paulo, Margarida Guedes Nogueira, sobrinha de Dona 0livia, e Dulce do Amaral Pinto, filha de Tarsila do Amaral.

Ao longo do percurso, vai registrando suas impressões em um diário, com a intenção de transformá-10 em um futuro "livro de viagens", ao qual chamaria 0 * Mestre em Letras: Estudos Literários (Área de concentração: Teoria da Literatura), 2000. 


\section{EM TESE}

Belo Horizonte, v. 5, p. I-305, dez. 2002

Turista Aprendiz. Regressando a São Paulo e começando a trabalhar imediatamente no Diário Nacional, explora uma pequena parte do material resultante dessa ida ao Norte: o diário e as notas de pesquisa. No final do ano de 1928, vai ao Nordeste, e de lá envia as crônicas publicadas simultaneamente no mesmo jornal. Embora continue a rever o livro de viagens, com o passar do tempo interrompe o trabalho e mesmo abandona o projeto, para retomá-10 em 1942, decidindo publicá-10 em 1943, sem no entanto ter realizado a elaboração definitiva pretendida.

Com a sua morte, em 1945, o projeto ficou suspenso, e o texto só foi editado em 1977, depois que o arquivo do escritor tornou-se patrimônio do Instituto de Estudos Brasileiros da Universidade de São Paulo, IEB-USP. A edição reúne as duas "viagens etnográficas": o diário da viagem ao Norte e as crônicas escritas durante a excursão ao Nordeste, sob o título 0 Turista Aprendiz, cuja Introdução e Notas elaboradas por Telê Porto Ancona Lopez são importantes para a compreensão da estrutura da obra. Como objeto de análise, uso apenas o texto da viagem ao Norte, no qual pode-se observar o hibridismo dos gêneros, uma dominante na literatura contemporânea e que já se nota particularmente nessa obra modernista. Por outro lado, a leitura desse texto possibilita desenvolver reflexões sobre a importância que teve a Amazônia no projeto de Mário de Andrade, na construção de uma identidade cultural para o país.

0 Prefácio, escrito dezesseis anos depois, serve para Mário recolocar algumas idéias sobre o projeto que o envolvia completamente naquele momento da viagem ao Amazonas. Confessa que estava "resolvido a ... escrever um livro modernista, provavelmente mais a escrever que viajar", "tomou muitas notas" mas, segundo ele, "quase tudo anotado sem nenhuma intenção da obra-de-arte", revelando o seu desejo de, nesse primeiro momento, não dar a conhecer aos outros a terra viajada e sim observar a Amazônia mais com vistas a futuros estudos sobre música e danças dramáticas, que se realizavam justamente nesse período. De fato, ao cruzar os rios da Amazônia, na época das festas juninas, Mário coleta vasto material etnográfico inserido no Ensaio sobre a música brasileira, assim como elementos de pesquisa literária levados para o Macunaíma, ambos publicados no ano seguinte ao da viagem, em 1928. 
No Prefácio, Mário destaca o caráter fragmentário do texto que resultou dessa viagem à Amazônia, enquanto diário, crônica ou narrativa da memória: as "notas telegráficas" muitas vezes se alongaram um pouco mais, resultado do tempo disponível na rotina da vida de bordo e coincidem com as muitas paradas feitas durante a viagem, ou ainda "sugeridas pelos descansos forçados do vaticano de fundo chato, vencendo a difícil torrente do rio". 0 escritor decidiu, porém, publicá-las "como estava nos cadernos e papéis soltos, ora mais ora menos escrito". Revela-se também o caráter complexo do texto narrativo, enquanto Mário denomina-o ora como viagem etnográfica, ora como diário ou livro de viagem, ora como notas e apontamentos do percurso, publicados, de acordo com ele, como crônicas e certos episódios tomados como contos, acentuando-1hes seu autor essas múltiplas características. Segundo a pesquisadora Telê Porto Ancona Lopez, Mário deixa evidente em várias de suas anotações o projeto de diário, transformando-o, porém, em um relato híbrido em que o real se mistura com o ficcional. Se por um lado, pretende guardar as "sínteses absurdas apenas pra uso pessoal", por outro, "as literatices são jogadas noutro caderninho em branco, em papéis de carta, costas de contas, margens de jornais, qualquer coisa serve". Lamentavelmente, muitas dessas anotações desapareceram deixando os pesquisadores sem saber, até que ponto, certos acontecimentos registrados no diário foram transformados depois em textos ficcionais pela imaginação do escritor.

Em carta que Manuel Bandeira situa em novembro de 1927, posterior portanto à viagem e durante o período em que escreve Macunaíma, Mário satiriza os cronistas viajantes, "mentirosos a valer". Com essa expressão, o escritor nos dá pistas para entender a sua narrativa de viagem como a de um cronista ficcionista, recriando as pequenas cidades do interior com seus habitantes, dimensionados magicamente em outro mundo amazônico. É então que se revela como o escritor que propositadamente inventa, lançando mão inclusive do maravilhoso para examinar o real e transformá10 em ficcional: Santarém surge das águas em "estranhas sensações venezianas" e Itacoatiara com seus "setecentos palácios triangulares". Os rios amazônicos transformam-se em "ruas líquidas", cujo "modo de condução habitual é o peixe-boi e, pras mulheres, o boto". Assim, o diário deixa de ser simplesmente a forma de narrar escolhida pois, ao elevar o discurso à condição de texto ficcional, indica a solução estrutural encontrada pelo cronista que se volta para a criação. 


\section{EM TESE}

Belo Horizonte, v. 5, p. I-305, dez. 2002

0 olhar modernista do escritor irônico descobre uma outra Belém, "cidade principal da Polinésia", onde identifica peculiaridades que a seus olhos adquiriam um sabor de ficção: "o sujeito passeando com um porco-do-mato na correntinha..."; "o indivíduo que ia de cartola, rabo de sobrecasaca abanando", com aquele calor "fantástico", uma de suas ironias ao clima da cidade. A sua fina ironia surge também na crônica de primeiro de junho, ao relatar que "é costume os jacarés aparecerem sempre nessa data nos igapós de beira rio, pra os turistas" (ele naturalmente) "poderem contemplá-los com satisfação".

Observando as diferenças entre seu mundo de paulista europeizado e o mundo tropical visitado, parte para a ficção explícita, explorando os recursos do fantástico, do insólito. Este quer ao nível da realidade de um mundo hiperbólico, mítico ou contraditório, quer ao nível do dado ficcional puro, exibido através do humor ou em uma atmosfera de sonho, de encantamento, será característica do texto dessa viagem. Se tudo na Amazônia, até hoje, é representado em termos hiperbólicos, Mário vai utilizá-los como o extraordinário dentro da narrativa. Os "biliões e biliões de carapanãs", a "borboleta de três metros e vinte de uma ponta à outra da asa", os "jacarés de doze metros", os "setecentos palácios triangulares de Itacoatiara", a "embaúva gigante de setecentos metros", todos são "personagens que eu invento". As "lendas etiológicas se prestam muito para a fantasia", diz ele. Reaproveita assim todo o mundo lendário amazônico: a lenda da Tapera da lua, da iara, do boto, a tribo dos índios Dó-mi-sol, a cidade afundada em Sapucaiaoroca e, ao recriá-las, utilizase também de um "vocabulário de pura fantasia", que reaparecerá em muitos de seus poemas e escritos posteriores. Revelando claramente seu trabalho de ficcionista na criação de lendas como a dos "Pacaás Novos" ou da tribo "Dó-mil-sol", ou inserindo esboços de seu trabalho de narrador como em "Perdidos" e, ao mesmo tempo, explorando a categoria do insólito ou do nonsense em "São Tomás e o Jacaré", e a descrição em o "Peixe-Boi", Mário é o prosador moderno, na medida em que tenta com seus recursos de expressão captar criticamente o momento em que vive, utilizando-se para isso do jogo da literatura com o maravilhoso amazônico.

Observa-se ainda no diário, o tom confessional que se vai misturando ao elemento ficcional inserido na narrativa: "nestes apontamentos de viagem' [... ], 
às vezes eu paro hesitando em contar certas coisas, com medo que não me acreditem", ou quando dá ao real, ao vivencial, um tratamento de conto ou ainda quando caracteriza suas companheiras de viagem como personagens autônomas dentro de uma obra literária: os nomes Dolur e Mag se alternam com os apelidos Trombeta e Balança, estes surgidos nessa viagem à Amazônia, além de mais dois apelidos, Eulália e Magnólia, primeira tentativa de nomear as suas jovens companheiras de viagem como personagens de futuro livro. 0 aspecto confessional do diário revela-se também quando o cronista narra suas emoções ou quando rememora os acontecimentos do dia, nas longas horas em que permanecia trancado na sua cabina, querendo "resumir" suas impressões da viagem, e entre aturdido e maravilhado, confessa o quanto é difícil seu intento. 0 escritor então aparece não apenas como o cronista que narra objetivamente, mas também como o cronista de si mesmo revelando sentimentos e emoções.

Assim, Mário, escritor modernista, constrói a ficção a partir da própria realidade experimentada ou observada, cruzando-a em seus aspectos real e ficcional, e confirma o interesse de nossos modernistas pela exploração de novos textos, que desbordam de compartimentos estanques denominados gêneros literários evoluindo para uma idéia mais atual de produção textual. A escolha da crônica, gênero conscientemente fragmentário, pois não pretende captar a totalidade dos fatos, ajuda Mário na sua tarefa de narrar a viagem em seus múltiplos aspectos dentro da estrutura de diário. Naturalmente, ao rever a redação dessa narrativa de viagem ao Norte, Mário tem a possibilidade de repensar a estrutura definitiva da obra, utiliza anotações constantes das notas para modificar o texto original, enquanto manipula tempo e espaço atribuindoThes características literárias.

$\mathrm{Na}$ viagem, vivendo apaixonadamente a região, Mário extravasa o gozo em diversos momentos de sua narrativa, enquanto vai registrando não só as paisagens mas também peculiaridades regionais, fundindo o referencial aos recursos poéticos, e revelando o caráter profundo com que vive suas experiências: "estou estourando de luar", luz que assombra o escritor ao pousar-1he "nos olhos, na boca, no sexo, nas mãos indiscretas", despertando-1he sensações eróticas. 0 prazer de ver transformase em experiência sensual e sexual, provocada pelo contato com o meio amazônico, que contagia o escritor de modo sensorial, embriagador. Destaca assim a impressão da 


\section{EM TESE}

Belo Horizonte, v. 5, p. I-305, dez. 2002

viagem e o êxtase com que viveu esses momentos de ócio amazônico, "o exílio da preguiça elevada", chave para o entendimento de sua tese sobre a criação de uma civilização tropical, esboçada durante a viagem.

Viajando por aquele "mundão de águas", Mário vai descobrindo a cultura amazônica. 0 escritor tem seus ouvidos atentos às músicas da região, ao detalhe da oralidade, às orquestras com "um chorinho gemido e humilde", os instrumentos básicos da orquestração "violino, cavaquinho e văria percussão inventada, com um pau batendo numa garrafa", a música criativa e híbrida brasileira tão bem definida por ele próprio, em muitos de seus ensaios sobre a nossa música popular e erudita. Mário vê as tradições culturais por toda parte, nas cantigas do "Boi Caprichoso", nas quadrilhas do "bumba-meu boi", nos escritos dos marujos nas gaiolas, nos cascos das embarcações. E no desejo de estar junto do povo, fonte de toda a cultura popular, que vai mesclando à erudita, acaba o seu dia "escutando cantigas na terceira classe, entre tapuios simpáticos e pacientes". Mário ouve muitas vozes. Valsas misturam-se a maxixes, óperas a cantos gregorianos, hinos nacionais a cantos folclóricos cantados pelos estrangeiros e brasileiros que viajam juntos no vaticano. Em plena seiva amazônica ecoam cantos litúrgicos: "tantum ergo" virando acalanto nas vozes escondidas nas margens dos rios, ladainhas ao canto chão nas pequenas igrejas perdidas na floresta, testemunhando o hibrídismo de nossa cultura. Mário admite: "pra ser brasileiro precisa vir ao Amazonas", e assim nos dá uma das chaves para se entender o seu pensamento, o olhar múltiplo que lança sobre o Brasil, sinalizando para o resgate da riqueza cultural amazônica, manifestada na música, na dança, no artesanato, na literatura popular e na culinária, e na inserção da região no mapa cultural do país.

Ao sair do conforto de sua casa, de seu quarto em São Paulo, trocandoo por uma apertada cabina de bordo, Mário de Andrade elege a Amazônia, o espaço da narrativa, a viagem, como locais ideais para pensar a cultura, para pensar a nação. No barco, espaço em constante movimento por entre as curvas dos rios, escreve-se o diário, misturam-se línguas e nacionalidades, cruzam-se identidades. 0 espaço da viagem confunde-se com o espaço da narrativa. Mário constrói a imagem de um barco babélico, tem a noção do navio "cheio, multidão de pessoas que tomam horrivelmente 
o lugar. Não há tolda, não há lugar nenhum em que eu não sinta pessoas em redor". Essa multidão de vozes é a voz dos que vão para a Amazônia trabalhar nos seringais, nos castanhas, nas serrarias. Dos nordestinos que imigram, que vão em busca de outros mundos, outros sonhos. Vozes que são ouvidas por Mário entre tantas vozes e que ele buscava indo diariamente para a terceira classe ouvir cantigas, casos, histórias de assombração, lendas de todo o Brasil: "Tenho nesta viagem pelo Madeira, tomado muito o costume de, após a janta, descer na terceira pra conversar".

Mário ele próprio um contador, narrador-viajante, guarda na memória esses momentos de convívio fraterno, que vai reproduzir em seus escritos. Do diálogo encetado com esses contadores, infere-se a permanente preocupação de Mário, de não consentir que essa arte desapareça, para preservar uma cultura e uma tradição, que fazem parte da cultura brasileira como um todo. Mário registra em seu caderninho tudo o que vê e ouve, ansioso para que não se percam essas manifestações culturais e que se documentem, através do seu registro escrito, os casos ouvidos, as lendas, os cantos, para que se acrescente, à memória histórica da região, que ele tenta preservar, a versão daqueles que nela vivem. No barco, ocorre o cruzamento de culturas de várias regiões do país e do mundo. Lá na noite amazônica, Mário escuta as mesmas histórias de assombração, lendas do ciclo da cidade afundada, que ouviu em Lagoa Santa, Minas Gerais, registro do pesquisador que quer salvar a tradição oral pela sua memória e salvando assim a memória nacional. 0 que Mário ouve na Amazônia deixa-1he marcas, que vão ressurgir seja em seus textos ensaísticos, ficcionais ou poéticos.

Ao escrever sobre a região amazônica, Mário procurava descobrir e valorizar o Brasil, entendê-10 enquanto vida e cultura de um povo que tem direito a manifestar sua diferença, e, ao mesmo tempo, inserir as diversas manifestações culturais brasileiras no projeto de dar uma unidade cultural ao país. Enquanto fotografa a região, realiza um complexo inventário com profundo sentimento pessoal e social, privilegiando questões ecológicas e etnográficas ao enfocar temas pertinentes e atuais, seja os que dizem respeito à conservação da floresta ou à preservação da cultura indígena na Amazônia. Ao mesmo tempo, coleciona objetos representativos da cultura amazônica, na tentativa de preservar a memória cultural da região. 


\section{EMTESE}

Belo Horizonte, v. 5, p. I-305, dez. 2002

Com sua viagem à Amazônia, o escritor percorreu um longo caminho, ajudando a compor o desenho de uma identidade cultural para o Brasil, que, nas décadas posteriores, será ampliado com obras de outros escritores e poetas brasileiros. Mário de Andrade, com o seu diário, recorrendo a vários tipos de relatos, do cronista de viagem, do viajante que documenta, do protagonista narrador de ficção, e do cronista de jornal que conta os acontecimentos do presente, lança o seu diverso olhar sobre a Amazônia, mostra o seu difícil aprendizado como turista em terra estranha, enquanto elabora o processo de sua interpretação cultural fundado na diversidade da nação brasileira.

ABSTRACT :

This study analyses Mário de Andrade's trip to the Amazon region, trying to evaluate the work "O turista aprendiz" according to Modernist concepts. To do so, it is based on the work of theorists who investigated the author's work, as well as that period in Brazilian Literature. It examine how the Amazon region is represented in foreigner traveler's texts, contrasting with modernist Mário de Andrade's point of view. It analyses some photos taken by him along the trip, and bis role as a cultural goods collector and defenser of Brazilian Cultural Patrimony.

KEY WORDS: Mărio de Andrade, modernism, trip, Amazon. 
ANDRADE, Mário de. O turista aprendiz. Ed. prep. por Telê Porto Ancona Lopez. São Paulo: Duas Cidades, 1983. ANDRADE, Mário de. Ensaio sobre a música brasileira. São Paulo: Martins, 1962.

ANDRADE, Mário de. Macunaíma: o herói sem nenhum caráter. Ed. crítica prep. por Telê Porto Ancona Lopez. Paris: Coleção Archivos, 1988.

ANDRADE, Mário de, e Bandeira, Manuel. Correspondência. Org. introd. e notas de Marcos Antonio de Moraes. São Paulo: EDUSP/IEB, 2000.

ANDRADE, Mário de. Táxi e crônicas no Diário Nacional. Ed. prep. por Telê Porto Ancona Lopez. São Paulo: Duas Cidades, 1976.

MÁRIO DE ANDRADE: fotógrafo e turista aprendiz. São Paulo: Instituto de Estudos Brasileiros-IEB/USP, 1993.

SOUZA, Gilda de Mello e. O colecionador e a coleção. Coleção Mário de Andrade - Artes Plásticas. São Paulo: IEB-USP, 1984, p. XI-XVII. 